\title{
Acil Serviste Yapılan Kan Transfüzyonları Acil Servis İşleyişini Etkiliyor mu?
}

\author{
Melih YÜKSEL, Halil KAYA, Suna ERAYBAR ATMACA, Hüseyin AYGÜN, \\ Mehtap BULUT
}

Sağlık Bilimleri Üniversitesi Bursa Yüksek İhtisas Eğitim ve Araştırma Hastanesi Acil Tıp Kliniği, Bursa.

\section{ÖZET}

Bu çalışmanın amacı acil serviste yapılan kan ve kan ürünleri transfüzyonlarının acil servis işleyiş̧ini etkileyip etkilemediğini araştırmaktır. 01.08.2019 ile 31.12.2019 tarihleri arasında Sağlık Bilimleri Üniversitesi Bursa Yüksek İhtisas Eğitim ve Araştırma Hastanesi Acil Servisi'nde kan ve kan ürünü transfüzyonu yapılan hastalar çalışmaya dahil edildi. Çalışmaya alınan hastaların yaş, cinsiyet, yapıllan transfüzyon türü ve sayısı, kan grubu, kan bekleme süresi, transfüzyon işlem süresi ve acil servisteki toplam kalıs süresi değişkenleri kaydedildi. Toplam

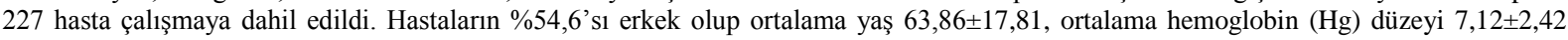
$\mathrm{g} / \mathrm{dL}$, ortalama kan bekleme süresi $6,44 \pm 3,02$ saat, ortalama transfüzyon işlem süresi 3,54 $\pm 3,45$ saat, ortalama toplam acil serviste kalış süresi 10,13 $\pm 4,00$ saat olarak saptandı. Hastaların \%74,0' ünde anemi tanısı mevcut idi. Oneway Anova testi ile yapılan analizde acil serviste toplam kalış süresi ile hasta tanıları arasında anlamlı fark olduğu görüldü $(F=4,235 ; \mathrm{p}=0.001)$. Post hoc tukey testi ile farkın koagülasyon bozuklukları ile anemi $(\mathrm{p}=0.001)$ ve koagülasyon bozuklukları ile gastrointestinal sistem kanamalarından ( $\mathrm{p}=0.013)$ kaynaklandığı saptandı. Acil endikasyonu olmayan kan ve kan ürünleri transfüzyonlarının acil servislerde yapılması acil servis yoğunluğuna ve hastaların bekleme sürelerinin uzamasına neden olmaktadır. Dolayısıyla bu işlemlerin acil servislerde yapılması acil servis işleyişini olumsuz yönde etkilemektedir.

Anahtar Kelimeler: Anemi. Bekleme Süresi. Kan Transfüzyonu. Trombositopeni. Acil Servis.

Does Blood Transfusions in the Emergency Department (ED) Adversely Affect the Operations in the ED?

\begin{abstract}
The goal of this study is to investigate whether blood and blood products transfusions in the emergency department (ED) affect the operations in the ED. Patients who were subjected to blood and blood product transfusions in the ED at the Health Sciences University Bursa Yüksek İhtisas Training and Research Hospital between 01.08.2019 and 31.12.2019 were included in the study. The patients were classified with regard to age, gender, transfusion type and numbers, blood type, waiting duration for blood, duration of transfusion operation, and total hospitalization period in the ED. In total, 227 patients were included. $54.6 \%$ of the patients were male and the average age was $63,86 \pm 17,81$. The average hemoglobin $(\mathrm{Hg}$ ) level was 7,12 $\pm 2,42 \mathrm{~g} / \mathrm{dL}$, the average blood waiting duration 6,44 $\pm 3,02$ hours, average transfusion operation duration was 3,54 $\pm 3,45$ hours, and the average total service in the ED was $10,13 \pm 4,00$ hours. $74,0 \%$ of the patients had been diagnosed with anemia. Through the one-way Anova test, it was observed that there was a meaningful difference between the total service time and the diagnosis $(\mathrm{F}=4,235 ; \mathrm{p}=0.001)$. With the post-hoc Tukey test, it was determined that the difference arose from coagulation abnormalities and anemia $(\mathrm{p}=0.001)$ and coagulation abnormalities and gastrointestinal hemorrhages $(\mathrm{p}=0.013)$. Blood and blood product transfusions with no associated emergency indicators contribute to additional load and longer waiting times in the ED. Therefore, conducting these operations in the ED adversely affects the operational capacities of the ED.
\end{abstract}

KeyWords: Anemia. Waiting Time. Blood Transfusion. Thrombocytopenia. Emergency Department.

Geliş Tarihi: 23.Mart.2020

Kabul Tarihi: 03. Haziran.2020

Dr. Melih YÜKSEL

Sağlık Bilimleri Üniversitesi Bursa Yüksek İhtisas Eğitim ve Araştırma Hastanesi, Acil Tıp Kliniği,

Mimar Sinan Mah. Polis Okulu karşısı

Yıldırım/Bursa

Tel: 05326013107

E-posta: melihdr@gmail.com

Yazarların ORCID ID Bilgisi:

Melih YÜKSEL: 0000-0002-0793-3693

Halil KAYA: 0000-0003-2005-6100

Suna ERAYBAR ATMACA: 0000-0003-4306-9262

Hüseyin AYGÜN: 0000-0002-8933-313X

Mehtap BULUT: 0000-0003-2131-9099
Acil servisler, tanisal tetkiklerin ve tedavi protokollerinin eş zamanlı yürütüldüğü 24 saat kesintisiz hizmet sunulan birimlerdir. Kritik hasta bakımında önemli bir yeri olan kan transfüzyonları acil serviste travma ve akut kan kaybı gibi durumlarda önemli bir uygulama olarak tedavide yerini almışıtır. Kan, her biri ayrı fonksiyonları olan spesifik yapılardan oluşmuş canlı bir dokudur. Kan transfüzyonu, doku transplantasyonuna eş değer olup beraberinde birçok risk barındıran önemli bir tedavidir ${ }^{1}$. Çoğu kez hayat kurtarıcı iken, yanlış endikasyonlar ile ölümcül bir nitelik kazanabilir. Kan transfüzyon tedavisini üstlenen hekimin transfüzyon reaksiyonları konusunda bilgi düzeyinin yüksek 
olması ve özellikle transfüzyon sırasında hastanın yakın vital takibinin yapılması büyük önem taşır ${ }^{2}$. Hastalarda önemli riskler göz önüne alınarak başlanan transfüzyonun acil servisteki amacı hastanın anstabil durumunu düzeltmek ya da kaybedilen kanın yerine konması olmalıdır. Travmalar, aktif gastrointestinal sistem (GIS) kanamaları, warfarin overdozu gibi hayati risk oluşturan endikasyonlar da acil tıp hekimi riskleri göze alarak hastaya gerekli transfüzyonlar ile müdahale etmektedir.

Kanın acil serviste kullanımında en önemli nokta uygun endikasyonda doğru seçilmiş kan bileşenlerinin kullanılmasıdır. Günümüzde ise nüfusun artması, kronik hastalıklarla acil servis başvuruları, poliklinik değerlendirmeleri sonucu saptanan kronik anemi gibi patolojilerin acil servise yönlendirilmesi nedeniyle acil hekiminin koymadığı endikasyonlara da transfüzyon yapılmaktadır. Bu durum kalabalık acil servislerde hasta takip olanaklarını zorlamakta, istenmeyen reaksiyonların görülme sıklığını arttırmakta ve hastaların acil serviste kalım süresini arttırarak acil servislerin hızlı ve etkin çalışma şeklini bozmaktadır ${ }^{3}$. Çalışmamızın amacı hastanemiz acil servisinde çeşitli nedenlerle kan transfüzyonu yapılan hastaların demografik özellikleri yapılan transfüzyon türü, acil serviste bekleme süreleri, geliş laboratuvar değerlerini retrospektif olarak inceleyip kan transfüzyon işleminin acil servis işleyişini etkileyip etkilemediğini araştırmaktır.

\section{Gereç ve Yöntem}

Çalışma 01.08.2019 ile 31.12.2019 tarihleri arasında Bursa Yüksek İhtisas Eğitim ve Araştırma Hastanesi Acil servisinde retrospektif olarak yürütüldü. Çalışma planlama sürecinde hastanemiz etik kurulundan 2011KAEK-25 2020/01-02 sayılı onayı alındı ve Araştırma ve Yayın Etiği ilkelerine uyuldu. Çalışmaya acil serviste kan ve kan ürünü transfüzyonu yapılan hastalar Hastane Bilgi Yönetim Sistemi (HBYS) ve hasta dosyaları taranarak dâhil edildi. Çalışmaya alınan hastaların yaş, cinsiyet, geliş laboratuvar değerleri, yapılan transfüzyon türü ve sayısı, kan grubu, kan bekleme süresi, transfüzyon işlem süresi ve acil servisteki toplam bekleme süresi değişkenleri kaydedildi. 18 yaş üstü acil serviste kan transfüzyonu yapılan tüm hastalar çalışmaya dahil edildi. 18 yaş altı kişiler ve dosya bilgileri eksik olan hastalar çalışma dışı bırakıldı. Toplam 233 hastanın dosyasına ulaşıldı. Beş hastanın dosya bilgilerine ulaşılamadığ 1 için 1 hasta da 18 yaşından küçük olduğu için çalışma dışı bırakıldı.

\section{Istatistiksel Analiz}

Hastalara ait tüm veriler olgu veri formuna kaydedilerek SPSS for Windows 22.0 programında analiz edildi. Çalışma verileri değerlendirilirken tanımlayıcı istatistiksel metotlar (ortalama, standart sapma, medyan, frekans, yüzde, minimum, maksimum) kullanıldı. Verilerin normal dağılıma uygun olup olmadığını analiz etmek için Kolmogorov-Smirnov testi kullanıld1. Birbirinden bağımsız ikiden fazla grubun aritmetik ortalamaya göre anlamlı bir farklılığının olup olmadığını araştırmak için One way Anova testi kullanıldı. Gruplar arasındaki anlamlı farklılı̆̆ın hangi gruplardan kaynaklandığını araştırmak için pos hoc tukey ve Tamhane testi kullanıldı. Korelasyon analizini yapmak için, parametrik değişkenlerde pearson testi, nonparametrik değişkenlerde ise spearman testi kullanıldı. P değerleri $<0.05$ olanlar anlamlı kabul edildi.

\section{Bulgular}

Çalışmaya toplam 227 hasta dahil edildi. Hastaların \%54,6's1 erkek olup ortalama yaş $63,86 \pm 17,81$, ortalama hemoglobin (Hg) düzeyi 7,12 $\pm 2,42 \mathrm{~g} / \mathrm{dL}$ olarak saptandı (Tablo I). Ortalama kan bekleme süresi $6,44 \pm 3,02$ saat, ortalama transfüzyon işlem süresi 3,54 $\pm 3,45$ saat, ortalama toplam acil serviste kalış süresi 10,13 $\pm 4,00$ saat olarak ölçüldü. Kan transfüzyonu yapılan anemi tanılı hastaların bu işlem için ortalama toplam acil serviste kalış süresi 10,36 $\pm 3,54$ saat olarak saptandı (Tablo II). Hastaların \%74,0'ünde anemi tanısı mevcut idi (Tablo III). En fazla transfüzyon yapilan kan grubu \%38,8 ile A Rh (+) olarak saptandı (Tablo IV). Olguların \%86,6'sına sadece eritrosit süspansiyonu (ES) verildi (Tablo V).

One way Anova testi ile yapılan analizde acil serviste toplam kalış süresi ile hasta tanıları arasında anlamlı fark olduğu görüldü $(F=4,235 ; p=0.001)$. Post hoc tukey testi ile farkın koagülasyon bozuklukları ile anemi ( $p=0.001)$ ve koagülasyon bozuklukları ile GISS kanamalarından $(\mathrm{p}=0.013)$ kaynaklandığ 1 saptandı (Tablo VI).

Tablo I. Değişkenlerin Frekans ve Yüzdelik Tablosu

\begin{tabular}{|c|c|c|c|c|c|c|}
\hline & Sayı(n) & Minimum & Maksimum & Ortalama & $\begin{array}{c}\text { Standart } \\
\text { Sapma }\end{array}$ & Varyans \\
\hline Yaş & 227 & 18 & 99 & 63,8678 & 17,81146 & 317,248 \\
\hline $\begin{array}{l}\text { Hemoglobin } \\
\text { değeri(g/dL) }\end{array}$ & 227 & 1,7 & 16,4 & 7,1223 & 2,42964 & 5,903 \\
\hline $\begin{array}{l}\text { Verilen Ünite } \\
\text { Sayısı(n) }\end{array}$ & 227 & 1 & 7 & 1,7665 & 0,92321 & 0,852 \\
\hline $\begin{array}{l}\text { Kan Bekleme } \\
\text { Süresi(saat) }\end{array}$ & 227 & 00,19 & 16,40 & 06,44 & 03,02 & 120064833,9 \\
\hline $\begin{array}{l}\text { Transfüzyon } \\
\text { Işlem } \\
\text { Süresi(saat) }\end{array}$ & 227 & 00,15 & 23,00 & 03,54 & 03,45 & 183618803,3 \\
\hline $\begin{array}{l}\text { Acilde toplam } \\
\text { Kalış } \\
\text { Süresi(saat) }\end{array}$ & 227 & 01,56 & 23,00 & 10,13 & 04,00 & 208566444,9 \\
\hline
\end{tabular}




\section{Acil Serviste Kan Transfüzyonu}

Tablo II. Tanılar ile değişkenlerin karşılaştırılması

\begin{tabular}{|c|c|c|c|c|}
\hline Tanı & & $\begin{array}{c}\text { Kan Bekleme } \\
\text { Süresi } \\
\text { (Saat) }\end{array}$ & $\begin{array}{l}\text { İşlem Süresi } \\
\text { (Saat) }\end{array}$ & $\begin{array}{c}\text { Acil Servis } \\
\text { Toplam Kalış } \\
\text { Süresi(Saat) }\end{array}$ \\
\hline \multirow[b]{2}{*}{ Anemi } & \multirow{2}{*}{$\begin{array}{l}\text { Ortalama } \\
\text { Standart } \\
\text { sapma }\end{array}$} & 06,53 & 04,00 & 10,36 \\
\hline & & 02,52 & 03,36 & 03,54 \\
\hline \multirow[b]{2}{*}{ Travma } & \multirow{2}{*}{$\begin{array}{l}\text { Ortalama } \\
\text { Standart } \\
\text { sapma }\end{array}$} & 03,47 & 02,35 & 06,22 \\
\hline & & 00,56 & 03,35 & 02,49 \\
\hline \multirow{2}{*}{$\begin{array}{l}\text { GiS Kana- } \\
\text { ma }\end{array}$} & \multirow{2}{*}{$\begin{array}{l}\text { Ortalama } \\
\text { Standart } \\
\text { sapma }\end{array}$} & 07,04 & 04,49 & 10,58 \\
\hline & & 03,35 & 04,54 & 03,50 \\
\hline \multirow{2}{*}{$\begin{array}{l}\text { Koagülas- } \\
\text { yon Bozuk- } \\
\text { luğu }\end{array}$} & \multirow{2}{*}{$\begin{array}{l}\text { Ortalama } \\
\text { Standart } \\
\text { sapma }\end{array}$} & 05,14 & 03,07 & 06,57 \\
\hline & & 04,06 & 04,02 & 04,20 \\
\hline \multirow{2}{*}{$\begin{array}{l}\text { Trombosi- } \\
\text { topeni }\end{array}$} & \multirow{2}{*}{$\begin{array}{l}\text { Ortalama } \\
\text { Standart } \\
\text { sapma }\end{array}$} & 06,48 & 01,37 & 08,25 \\
\hline & & 01,44 & 01,25 & 02,21 \\
\hline \multirow[b]{2}{*}{ Diğer } & \multirow{2}{*}{$\begin{array}{l}\text { Ortalama } \\
\text { Standart } \\
\text { sapma }\end{array}$} & 08,27 & 03,30 & 11,57 \\
\hline & & 02,15 & 02,27 & 03,31 \\
\hline \multirow{3}{*}{ Total } & \multirow{3}{*}{$\begin{array}{l}\text { Standart } \\
\text { sapma } \\
\text { Toplam }\end{array}$} & 06,44 & 03,54 & 10,13 \\
\hline & & 03,02 & 03,45 & 04,00 \\
\hline & & 227 & 227 & 227 \\
\hline
\end{tabular}

GİS: Gastrointestinal Sistem

Tablo III. Kan Transfüzyonu Yapılan Hastaların Tanilar1

\begin{tabular}{|lcc|}
\hline & Sayı(n) & Yüzde(\%) \\
\hline Anemi & 168 & 74 \\
Travma & 4 & 1,8 \\
GiS Kanama & 26 & 11,5 \\
Koagülasyon Bozukluğu & 17 & 7,5 \\
Trombositopeni & 9 & 4 \\
Diğer & 3 & 1,3 \\
\hline Total & 227 & 100 \\
\hline
\end{tabular}

GIS: Gastrointestinal sistem

Tablo IV. Kan Transfüzyonu Yapılan Hastaların Kan Gruplar1

\begin{tabular}{|ccc|}
\hline & Sayı(n) & Yüzde(\%) \\
\hline ARH+ & 88 & 38,8 \\
ORH+ & 72 & 31,7 \\
BRH+ & 35 & 15,4 \\
ABRH+ & 10 & 4,4 \\
ARH- & 9 & 4 \\
ORH- & 8 & 3,5 \\
BRH- & 4 & 1,8 \\
ABRH- & 1 & 0,4 \\
\hline Total & 227 & 100 \\
\hline
\end{tabular}

Tablo V. Hastalara verilen kan ve kan ürünlerinin frekans ve yüzdelikleri

\begin{tabular}{|lcc|}
\hline & Sayı(n) & Yüzde(\%) \\
\hline ES & 192 & 84,6 \\
TDP & 16 & 7 \\
ES+TDP & 5 & 2,2 \\
TS & 12 & 5,3 \\
ES+TS & 2 & 0,9 \\
\hline Total & 227 & 100 \\
\hline
\end{tabular}

ES: Eritrosit Süspansiyonu, TDP: Taze Donmuş Plazam, TS: Trombosit Süspansiyonu
Tablo VI. Acilde toplam kalış süresinin tanı grupları ile karşılaştırılması

\begin{tabular}{|c|c|c|c|c|c|c|}
\hline \multirow[t]{2}{*}{ (I) Sonuç } & \multirow[t]{2}{*}{ (J) Sonuç } & \multirow{2}{*}{$\begin{array}{c}\text { Fark } \\
(\mathrm{I}-\mathrm{J}) \text { (saat) }\end{array}$} & \multirow{2}{*}{$\begin{array}{l}\text { Std. } \\
\text { Hata }\end{array}$} & \multirow[t]{2}{*}{ P } & \multicolumn{2}{|c|}{$\begin{array}{c}\text { 95\% Güven } \\
\text { Aralığı }\end{array}$} \\
\hline & & & & & Alt & Üst \\
\hline \multirow{5}{*}{ Anemi } & Travma & 4,13 & 1,57 & ,263 & $-1,24$ & 9,51 \\
\hline & Gis Kanama & $-0,22$ & 0,49 & ,998 & $-2,43$ & 1,58 \\
\hline & $\begin{array}{l}\text { Koagülasyon } \\
\text { Bozukluğu }\end{array}$ & $3,39^{*}$ & 0,59 & ,004 & 0,48 & 6,29 \\
\hline & Trombositopeni & 2,10 & 1,19 &, 571 & $-1,37$ & 5,59 \\
\hline & Diğer & $-1,20$ & 2,15 & ,991 & $-7,50$ & 5,08 \\
\hline \multirow{5}{*}{ Travma } & Anemi & $-4,13$ & 1,57 & ,263 & $-9,51$ & 1,24 \\
\hline & Gis Kanama & $-4,35$ & 2,04 & ,238 & 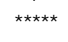 & 1,23 \\
\hline & $\begin{array}{l}\text { Koagülasyon } \\
\text { Bozukluğu }\end{array}$ & $-0,34$ & 2,09 & 1,000 & $-6,46$ & 5,36 \\
\hline & Trombositopeni & $-2,02$ & 2,19 & ,951 & $-8,44$ & 4,38 \\
\hline & Diğer & $-5,34$ & 2,57 & ,415 & 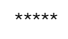 & 2,55 \\
\hline \multirow{5}{*}{$\begin{array}{l}\text { Gis } \\
\text { Kanama }\end{array}$} & Anemi & 0,22 & 0,49 & ,998 & $-1,58$ & 2,43 \\
\hline & Travma & 4,35 & 2,04 & ,238 & $-1,23$ & 10,34 \\
\hline & $\begin{array}{l}\text { Koagülasyon } \\
\text { Bozukluğu }\end{array}$ & $4,01^{*}$ & 1,12 & ,013 & 0,32 & 7,29 \\
\hline & Trombositopeni & 2,32 & 1,29 &, 533 & $-1,45$ & 6,51 \\
\hline & Diğer & $-0,58$ & 2,21 & ,998 & $-7,46$ & 5,48 \\
\hline \multirow{5}{*}{$\begin{array}{l}\text { Koagülas- } \\
\text { yon } \\
\text { Bozukluğu }\end{array}$} & Anemi & $-3,39$ & 0,59 & ,004 & $-6,29$ & $-0,48$ \\
\hline & Travma & 0,34 & 2,09 & 1,000 & $-5,36$ & 6,46 \\
\hline & Gis Kanama & $-4,01^{*}$ & 1,12 & ,013 & $-7,29$ & $-0,32$ \\
\hline & Trombositopeni & $-1,28$ & 1,35 & 941 & $-6,03$ & 3,07 \\
\hline & Diğer & $-4,59$ & 2,25 & ,312 & 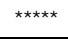 & 1,58 \\
\hline \multirow{5}{*}{$\begin{array}{l}\text { Trombosi- } \\
\text { topeni }\end{array}$} & Anemi & $-2,10$ & 1,19 & ,571 & $-5,59$ & 1,57 \\
\hline & Travma & 2,02 & 2,19 & 951 & $-4,38$ & 8,44 \\
\hline & Gis Kanama & $-2,32$ & 1,29 & ,533 & $-6,51$ & 1,45 \\
\hline & $\begin{array}{l}\text { Koagülasyon } \\
\text { Bozukluğu }\end{array}$ & 1,28 & 1,35 & ,941 & $-3,07$ & 6,03 \\
\hline & Diğer & $-3,31$ & 2,35 & ,748 & 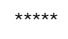 & 3,53 \\
\hline \multirow{5}{*}{ Diğer } & Anemi & 1,20 & 2,15 & ,991 & $-5,08$ & 7,50 \\
\hline & Travma & 5,34 & 2,57 & ,415 & $-2,55$ & 14,05 \\
\hline & Gis Kanama & 0,58 & 2,21 & ,998 & $-5,48$ & 7,46 \\
\hline & $\begin{array}{l}\text { Koagülasyon } \\
\text { Bozukluğu }\end{array}$ & 4,59 & 2,25 & ,312 & $-1,58$ & 11,58 \\
\hline & Trombositopeni & 3,31 & 2,35 & ,748 & $-3,53$ & 10,57 \\
\hline
\end{tabular}

Ortalama fark 0.05 düzeyinde anlamlıdır. GİS: Gastrointestinal sistem

Parametrik korelasyon analizi için yapılan pearson testinde, kan bekleme süreleri ile acil serviste toplam kalış süreleri arasında pozitif yönde anlamlı bir korelasyon saptand1 $(\mathrm{p}=0.000),(\mathrm{r}=0.633)$. Kan transfüzyon işlem süreleri ile acil serviste toplam kalış süreleri arasında da pozitif yönde anlamlı bir korelasyon saptand $1(\mathrm{p}=0.000),(\mathrm{r}=0,478)$. Yine hasta tanıları ile acil serviste toplam kalış süresi arasında negatif yönde anlamı bir korelasyon $(\mathrm{p}=0.0017),(\mathrm{r}=-0,158)$, hasta tanıları ile tedavi türü arasında da pozitif yönde anlamlı bir korelasyon saptand $1(\mathrm{p}=0.000),(\mathrm{r}=0,633)$.

\section{Tartışma ve Sonuç}

Günümüzde ortalama yaşam süresinin artması ile beraber kronik hastalıkların insidansı da artmaktadır. Kronik hastalıkların artması ile beraber kan ve kan ürünlerinin kullanımı da artmaktadır. Ülkemizde yapı- 
lan çalışmalarda acil serviste kan ve kan ürünlerinin transfüzyonu yapılan hastaların ortalama yaşları 60,661,3 olarak bulunmuştur ${ }^{3,4}$. Amerika Birleşik Devletleri'nde (ABD) yapılan bir çalışmada ise acil serviste kan transfüzyonu yapılan hastaların ortalama yaşı 62.0 olarak saptanmıștır ${ }^{5}$. Bizim yaptığımız çalışmada da kan transfüzyonu yapılan hastaların ortalama yaşı literatür ile uyumludur.

Ülkemizde transfüzyon yapılan hastaların cinsiyete göre dağılımını inceleyen çalışmalarda kadın popülasyonun oranlar1 \%39,0 - $\% \quad$ 59,8 arasinda saptanmıştır ${ }^{3,6,7}$ Yurt dışında yapılan bir çalışmada ise transfüzyon yapılan hastalarda kadın oranı \%52,9 olarak saptanmıştır ${ }^{5}$.Bizim çalışmamızda saptanan cinsiyet oranı da literatür ile uyumludur.

Acil servis ve diğer transfüzyon yapılan merkezlerde çeşitli endikasyonlar ile kan ve kan ürünlerinin transfüzyonları yapılmaktadır. Doğan ve ark.'larının yapmış olduğu bir çalışmada acil serviste, en fazla anemi tanısı (\% 49,2) ile transfüzyon yapıldığını saptamışlardır ${ }^{3}$. İşler ve ark.'larının da yapmış olduğu çalışmada yine en fazla anemi tanısı (\% 40,2) ile acil serviste transfüzyon yapıldığını saptamışlardır ${ }^{7}$. Beyer ve ark.' larının yapmış olduğu başka bir çalışmada ise acil serviste en fazla GİS kanamalı hastalara $(\% 22,1)$ transfüzyon yapıldı̆̆ı saptanmış ve yine bu çalışmada anemi tanılı hastaların oranı \% 10,8 olarak bulunmuştur ${ }^{5}$. Yoğun bakımlardaki transfüzyonları inceleyen bir çalışmada ise en fazla anemi tanılı hastalara transfüzyon yapıldığı bulunmuştur ${ }^{8}$. Yine Özgür ve ark.'larının yapmış olduğu çalışmada ise acil servislerde yapılan kan transfüzyonlarının \%47'sinin acil endikasyonu olduğu saptanmış ${ }^{6}$. Bizim çalışmamızda da ülkemizde yapılan çalışmalara benzer şekilde en fazla anemi tanılı hastalara $(\% 74,0)$ transfüzyon yap1lırken GIS kanama ve travma hastaları gibi acil olguların toplam transfüzyon oranları \%13,3 olarak saptanmıştır. Bu veriler sonucunda ülkemizde acil servislerde yapılan kan ve kan ürünlerinin transfüzyonlar1nın önemli bir kısmının acil endikasyonu olmadığ sonucu ortaya çıkmaktadır. Ayrıca transfüzyon ihtiyac1 olan ancak bu durumun aciliyet gerektirmediği hastalarda transfüzyon yapılmasını üstlenen acil harici kliniklerin olmaması da bu durumun nedeni olabilir.

Dünya'da tanımlanmış çeşitli kan grupları mevuttur. Ancak klinik açıdan en önemli kan grubu sistemleri ABO ve Rh'dır'. ABO ve Rh kan gruplarının dağılımı bir ülkedeki coğrafi durum ya da etnik dağılım arasında bile farklılık gösterebilmektedir ${ }^{9}$. Dünya genelinde en fazla bulunan kan grubu $\mathrm{O}$ kan grubudur ${ }^{10}$. Ülkemizde yapılan çalışmalarda ise en fazla bulunan kan grubu A Rh(+)'tir ${ }^{6,70-12}$. Bizim çalışmamızda da transfüzyon yapılan hastalarda en fazla saptanan kan grubu A Rh(+) olarak saptand.

Kan ve kan ürünleri içerisinde genellikle en fazla transfüzyon yapılan ürün ES'dir. Ülkemizde yapılan çalışmalarda acil serviste transfüzyon yapılan hastala- rın \%84,8-\%94,6'sına ES transfüzyonu yapıldığı bulunmuştur ${ }^{3,7}$. Bizim çalışmamızda da literatürde olduğu gibi en fazla ES transfüzyonu yapıldığı bulunmuştur.

Bizim çalışmamızda elde edilen en önemli bulgulardan birisi de transfüzyon yapılan hastaların ortalama kan bekleme süresinin 6,44 saat ile acil serviste ortalama kalış süresinin 10,13 saat çıkmasıdır. Bu hastaların büyük bir kısmı anemi tanısı alan hastalardır. Ülkemizde yapılan bir çalışmada, kan ve kan ürünleri transfüzyonu yapılan hastaların acil serviste toplam kalış süresi 17,03 saat olarak saptanmıştır. Bu çalışmada da en fazla transfüzyon yapılan hastaların anemisi olan hastalar olduğu görülmektedir ${ }^{3}$. Hem bizim çalışmamızda hem de Doğan ve ark.'larının yapmış olduğu çalışmada bu hastaların acil serviste kalış sürelerinin uzun olduğu saptanmıștır. Bu yüzden uzun kan bekleme ve kalış sürelerinin acil servis işleyişini olumsuz olarak etkilediğini düşünmekteyiz.

Ülkemizde yapılan yasal düzenlemeler ile tek kan ve kan ürünlerinin tedarikçisi olarak Kızılay kurumu yetkilendirilmiştir. Hastanelerin kan bankaları ihtiyaç duydukları kan ve kan ürünlerini Kızılay'dan temin etmektedir. Bu durum, bizim çalışmamızda da olduğu gibi kan bekleme sürelerinin uzamasında bir etken olabilir.

Kan ve kan ürünlerinin transfüzyonun yapıldığı yerler konusunda hastaneler çeşitli çözümler bulmuştur. Bazı hastaneler, sadece hafta içi mesai saatlerinde kan transfüzyon ünitesinde bu işlemi yapmakta iken bazı hastaneler de günü birlik servis yatışı yaparak bu işlemleri gerçekleştirmektedir. Bunların dışında kalan hastaneler ise bu işlemleri acil serviste yapmaya çalışmaktadır. Aynı zamanda sadece gündüz bu işlemlerin yapıldığı kan transfüzyon ünitelerinde, kan isteme ve işlem süreleri uzadığından bu hastalarda acil servislere yönlendirilmektedir. $\mathrm{Bu}$ durum da acil servis yoğunluğunun artmasına neden olmaktadır.

Bu çalışmanın retrospektif olması ve de çalışma popülasyonun az olmasının en önemli kısitlılık olduğunu düşünmekteyiz. Ayrıca dosyalardaki veri eksikliklerinden dolayı anemi tanısı alan hastaların ne kadarının acil transfüzyon ihtiyacı olduğunu hesaplayamadık.

Sonuç olarak günümüzde acil servislerdeki yoğunluk ve hastaların bekleme sürelerinin uzaması acil servislerin en büyük sorunlarının önemli bir kısmını oluşturmaktadır. Acil olmayan kan ve kan ürünlerinin transfüzyonlarının acil servislerde yapılması, acil servis yoğunluğuna ve bekleme sürelerinin uzamasına neden olmaktadır. Dolayısıyla bu işlemlerin acil servislerde yapılması acil servis işleyişini olumsuz olarak etkilemektedir. $\mathrm{Bu}$ işlemlerin hastanelerde kan transfüzyon ünitelerinde yapılmasının daha uygun olacağı kanaatindeyiz. 


\section{Acil Serviste Kan Transfüzyonu}

Etik Kurul Onay Bilgisi:

Onaylayan Kurul: Bursa Yüksek İhtisas Eğitim ve Araştırma Hastanesi Klinik Araștırmalar Etik Kurulu.

Onay Tarihi: 29.01.2020

Karar No: 2011-KAEK-25 2020/01-02

\section{Kaynaklar}

1. Küçüktaş P, Şahin İ, Çalışkan E, Kılınçel Ö. Düzce Üniversites Sağlık Uygulama Ve Araştırma Merkezi'nde Kan Ve Kan Bileşenlerinin Kliniklere Göre Kullanımlarının Değerlendirilmesi. Kocaeli Üniversitesi Sağllk Bilimleri Dergisi. 2019;5(1):25-28.

2. Delaney M, Wendel S, Bercovitz RS, et al. Transfusion reactions: prevention, diagnosis, and treatment. The Lancet. 2016;388(10061):2825-2836.

3. Doğan S, Bulut B, Kalafat UM, et al. Acil Serviste Kan ve Kan Ürünü Kullanılan Hastaların Geriye Dönük Değerlendirilmesi. IKSSTD. 2019;11(3):157-163.

4. KARAMURAT M, DURAK VA, KÖKSAL Ö. Bir Üniversite Hastanesi Acil Servisi'nde Taze Donmuș Plazma (TDP) Verilen Hastaların Retrospektif Analizi. Uludağ Üniversitesi Tip Fakültesi Dergisi. 2018;44(3):197-202.

5. Beyer A, Rees R, Palmer C, Wessman BT, Fuller BM. Blood product transfusion in emergency department patients: a case- control study of practice patterns and impact on outcome. International journal of emergency medicine. 2017;10(1):5.

6. Özgür Y, Akın S, Gecmez G, Aladağ N, Keskin Ö. How Urgent are Blood Transfusions Provided in Emergency Service? Southern Clinics of Istanbul Eurasia. 2018;29(3).

7. İŞLER Y, Halil K, ISSLER Ş, YÜKSEL M. Acil Serviste Kan Transfüzyonu Yapılan Hastaların Özellikleri. Uludăg Universitesi Tip Fakültesi Dergisi. 2019;45(3):275-280.

8. Bagci M, Özcan PE, Sentürk E, Telci L, Çakar N. Kritik Hastalarda Anemi ve Kan Transfüzyonlarinin Degerlendirilmesi/Evaluation of Anemia and Blood Transfusions in Critically Ill Patients. Türk Yogun Bakim Dergisi. 2014;12(2):45

9. Yildiz SM. Distribution of ABO and Rh blood group systems in Cukurova region. Cukurova Medical Journal. 2016;41(4):658663.

10. Eren C. İstanbul İlinde $\mathrm{ABO}$ ve Rh Kan Grupları Dağılımının Analizi. Dicle Tip Dergisi. 2019;46(2):48-51.

11. Kurt H, Yavuz T, Toprak Ö, Demirkıran D, Sarı Y. The relationship of $\mathrm{ABO}$ Blood groups with chronic renal failure. Eur J Health Sci. 2015;1:109-113.

12. Çekdemir D, Ergenc H, Ucar A, et al. Blood Groups Distributions of Donors/Patients in a Tertiary Hospital. Sakarya Tip Dergisi. 2018;8(4):753-758 
